\title{
Differences in whole-body fat oxidation kinetics between cycling and running
}

\author{
Xavier Chenevière $\cdot$ Davide Malatesta $\cdot$ \\ Boris Gojanovic · Fabio Borrani
}

Accepted: 11 March 2010/Published online: 1 April 2010

(C) Springer-Verlag 2010

\begin{abstract}
This study aimed to quantitatively describe and compare whole-body fat oxidation kinetics in cycling and running using a sinusoidal mathematical model (SIN). Thirteen moderately trained individuals ( 7 men and 6 women) performed two graded exercise tests, with 3-min stages and $1 \mathrm{~km} \mathrm{~h}^{-1}$ (or $20 \mathrm{~W}$ ) increment, on a treadmill and on a cycle ergometer. Fat oxidation rates were determined using indirect calorimetry and plotted as a function of exercise intensity. The SIN model, which includes three independent variables (dilatation, symmetry and translation) that account for main quantitative characteristics of kinetics, provided a mathematical description of fat oxidation kinetics and allowed for determination of the intensity $\left(\mathrm{Fat}_{\mathrm{max}}\right)$ that elicits maximal fat oxidation (MFO). While the mean fat oxidation kinetics in cycling formed a symmetric parabolic curve, the mean kinetics during running was characterized by a greater dilatation (i.e., widening of the curve, $P<0.001$ ) and a rightward asymmetry (i.e., shift of the peak of the curve to higher intensities, $P=0.01$ ). Fat ${ }_{\max }$ was significantly higher in running compared with cycling $(P<0.001)$,
\end{abstract}

Communicated by Klaas Westerterp.

This article is published as part of the Special Issue dedicated to Pietro di Prampero, formerly Editor-in-Chief of EJAP.

X. Chenevière $(\bowtie) \cdot D$. Malatesta $\cdot$ F. Borrani

Institute of Sport Sciences, University of Lausanne (ISSUL),

Bâtiment de Vidy, 1015 Lausanne, Switzerland

e-mail: xavier_cheneviere@yahoo.com

B. Gojanovic

Department of Locomotion, CHUV, Lausanne, Switzerland

F. Borrani

Department of Sport and Exercise Science,

University of Auckland, Auckland, New Zealand whereas MFO was not significantly different between modes of exercise $(P=0.36)$. This study showed that the wholebody fat oxidation kinetics during running was characterized by a greater dilatation and a rightward asymmetry compared with cycling. The greater dilatation may be mainly related to the larger muscle mass involved in running while the rightward asymmetry may be induced by the specific type of muscle contraction.

Keywords Exercise mode $\cdot$ Fat $_{\max } \cdot$ Maximal fat oxidation · Indirect calorimetry $\cdot$ Exercise intensity

\section{Introduction}

During aerobic exercise, carbohydrate $(\mathrm{CHO})$ and fat are the two main sources of energy that sustain oxidative metabolism, and their relative utilization depends largely on exercise intensity (Romijn et al. 1993; van Loon et al. 2001). In absolute terms, $\mathrm{CHO}$ oxidation increases with the workload, whereas fat oxidation rates increase from low to moderate exercise intensities, and then markedly decline at high intensities. The exercise intensity at which the maximal fat oxidation (MFO) rate occurs has been defined as $\mathrm{Fat}_{\max }$ (Achten et al. 2002). A Fat ${ }_{\max }$ zone has also been defined as the range of exercise intensities with fat oxidation rates that fall within $10 \%$ of MFO (Achten et al. 2002). Recently, a sinusoidal equation (SIN) has been developed to model and to quantitatively describe the shape of the whole-body fat oxidation kinetics, represented as a function of exercise intensity, during graded exercise and to determine Fat $_{\max }$ and MFO (Cheneviere et al. 2009b). Moreover, the degree of dilatation (i.e. widening) of the curve appeared to be a sensitive marker for the ability to oxidize fat (Cheneviere et al. 2009b). 
It is well documented that the pattern of whole-body fat oxidation kinetics, including MFO and $\mathrm{Fat}_{\text {max }}$, when presented as a function of exercise intensity, may be influenced by factors, such as diet (Bergman and Brooks 1999; Coyle et al. 2001), gender (Carter et al. 2001; Horton et al. 1998; Venables et al. 2005), training level (Bergman et al. 1999; Sidossis et al. 1998; Stisen et al. 2006) and body composition (Perez-Martin et al. 2001). Besides the abovementioned factors, the exercise mode may also influence fat oxidation. Previous studies (Knechtle et al. 2004; Nieman et al. 1998; Snyder et al. 1993) have shown a higher absolute fat oxidation during running compared with cycling at the same relative exercise intensities. Several possible reasons have been suggested to explain the higher fat oxidation rates during running. These include a smaller muscle mass involved in cycling (Arkinstall et al. 2001; Hermansen and Saltin 1969), differences in muscle contraction regimens (i.e., concentric vs. eccentric), and a greater mechanical efficiency in running due to the stretchshortening cycle (SSC) (Bijker et al. 2002; Carter et al. 2000). To our knowledge, only one study (Achten et al. 2003) compared substrate oxidation over a wide range of intensities in two different modes of exercise, but the authors compared cycling with uphill walking rather than running and the relevance for runners could therefore be questioned.

The aim of the present study was therefore to quantitatively describe and compare whole-body fat oxidation kinetics during graded exercise tests in cycling and running using a mathematical model. It was hypothesized that the higher fat oxidation rates over a wide range of intensities in running compared with cycling would induce a widening of the curve of the fat oxidation kinetics.

\section{Methods}

\section{Participants}

Thirteen healthy and moderately trained volunteers ( 7 men and 6 women) were recruited to participate in this study, which was approved by the local Research Ethics Committee. All individuals were non-smokers, disease-free, not taking any medication and were screened for the absence of electrocardiographic abnormalities. Each participant completed a self-reported measurement of habitual physical activity questionnaire divided into three sections: physical activity at work, sport during leisure time and physical activity during leisure excluding sport (Baecke et al. 1982). Typical activities were hockey, badminton, basketball, soccer and swimming. In addition, two individuals (1 man and 1 woman) were recreational cyclists $\left(\sim 4 \mathrm{~h} \mathrm{week}^{-1}\right)$, while four others (1 man and 3 women) were competitive cyclists $\left(>10 \mathrm{~h}\right.$ week $\left.^{-1}\right)$. All test procedures and risks associated with the experiment were fully explained, and the participants were asked to provide written consent for participation.

\section{Experimental design}

Each participant completed two test sessions. In the first session, body mass and stature were measured, and body composition [body fat mass, fat-free mass (FFM) and \% body fat] was estimated from skin-fold thickness measurements at four sites, according to the method of Durnin and Womersley (1973). Each participant then performed a maximal incremental exercise test on a cycle ergometer to determine $\dot{V} \mathrm{O}_{2 \max }$ and substrate oxidation. In a second session, the volunteers performed a maximal incremental exercise test on a treadmill. Prior to the experiment, the participants were familiarized with the equipment and procedures. The order of the two test sessions was assigned to the volunteers in a randomized cross-over design, and the trials were performed 3-7 days apart. Participants reported to the laboratory at the same time to avoid circadian variance, after a minimum 6-h fast period and with the same interval of time from the last meal. The volunteers were asked to fill in a 1-day food diary on the day before their first experimental test and to repeat this diet before the subsequent trial. Furthermore, the volunteers were requested to avoid strenuous exercise and drinking alcohol and caffeine for the $24 \mathrm{~h}$ preceding each test.

\section{Incremental tests}

Cycling protocol After a 3-min rest period, volunteers began with a 5-min warm-up at $40 \mathrm{~W}$ on a cycle ergometer (Ebike Basic BPlus, General Electric, Niskayuna, NY, USA), after which the workload was increased by $20 \mathrm{~W}$ every 3 min until the respiratory exchange ratio (RER) reached 1.0. At this point, the work rate was increased by $20 \mathrm{~W}$ every minute until exhaustion to obtain a measure of $\dot{V} \mathrm{O}_{2 \max }$ within a short time (Cheneviere et al. 2009b).

Running protocol After a 3-min rest period on a treadmill (Saturn HP Cosmos, Traunstein, Germany), volunteers walked for a 5-min warm-up at a speed of $3 \mathrm{~km} \mathrm{~h}^{-1}$ and a gradient of $1 \%$, which was followed by an increase of $1 \mathrm{~km} \mathrm{~h}^{-1}$ every $3 \mathrm{~min}$ until the speed of $7 \mathrm{~km} \mathrm{~h}^{-1}$ was reached. Participants were asked to walk for $3 \mathrm{~min}$ at this speed and then to start running for another $3 \mathrm{~min}$, after which the speed was increased by $1 \mathrm{~km} \mathrm{~h}^{-1}$ every $3 \mathrm{~min}$ until RER reached 1.0. At this point, the speed was increased by $1 \mathrm{~km} \mathrm{~h}^{-1}$ every minute until exhaustion (Cheneviere et al. 2009a). 
During the tests, heart rate (HR) was recorded continuously from an electrocardiogram (GE Cardiosoft Corina, GE Medical Systems, Freiburg, Germany). Oxygen uptake $\left(\dot{V} \mathrm{O}_{2}\right)$ and $\mathrm{CO}_{2}$ output $\left(\dot{V} \mathrm{CO}_{2}\right)$ were measured continuously using a breath-by-breath online system (Oxycon Pro, Jaeger, Würzburg, Germany). Oxycon Pro has been shown to be a valid and reliable (i.e., day-to-day and within day variations) system for generating accurate and repeatable respiratory data for $\dot{V} \mathrm{O}_{2}$ and $\dot{V} \mathrm{CO}_{2}$ during metabolic simulator and exercise compared with Douglas bags (Carter and Jeukendrup 2002). Moreover, before the study began, the validity and reliability of the metabolic card used in the present study were tested using a metabolic simulator. Before each test, the gas analyzers were calibrated with gases of known concentration $\left(16.00 \% \mathrm{O}_{2}\right.$; $5.02 \% \mathrm{CO}_{2}$ ) and the volume was automatically calibrated at flow rates of 0.2 and $2 \mathrm{~L} \mathrm{~s}^{-1}$.

For both tests, $\dot{V} \mathrm{O}_{2}$ was considered to be maximal when at least two of the following three criteria were met: (1) a levelling off of $\dot{V} \mathrm{O}_{2}$ (defined as an increase of no more than $2 \mathrm{~mL} \mathrm{~kg}^{-1} \mathrm{~min}^{-1}$ ) during the latter stages of the exercise test, (2) a $\mathrm{HR}>90 \%$ of the predicted maximum (220 beats $\min ^{-1}$ minus age) and (3) RER $>1.1 . \dot{V} \mathrm{O}_{2 \max }$ was calculated as the average $\dot{V} \mathrm{O}_{2}$ over the last $20 \mathrm{~s}$ of the last stage of the test. Ventilatory thresholds $1\left(\mathrm{VT}_{1}\right)$ and 2 $\left(\mathrm{VT}_{2}\right)$ were determined as described in the literature using the Wasserman's ventilatory method (Wasserman et al. 1994), while the estimate of $\mathrm{VT}_{1}$ was supported using the Beaver ventilatory method (Beaver et al. 1986). Two blinded and independent investigators determined $\mathrm{VT}_{1}$ and $\mathrm{VT}_{2}$.

\section{Indirect calorimetry and calculations}

During the incremental tests, average values for $\dot{V} \mathrm{O}_{2}$ and $\dot{V} \mathrm{CO}_{2}$ were calculated over the last minute of every stage, during which the RER $\leq 1.0$. Fat and $\mathrm{CHO}$ oxidation rates were calculated using stoichiometric equations (Frayn 1983) and appropriate energy equivalents, with the assumption that urinary nitrogen excretion rate was negligible:

Fat oxidation rate $\left(\mathrm{g} \mathrm{min}^{-1}\right)$

$$
=1.67 \dot{V} \mathrm{O}_{2}\left(\mathrm{~L} \mathrm{~min}^{-1}\right)-1.67 \dot{V} \mathrm{CO}_{2}\left(\mathrm{~L} \mathrm{~min}^{-1}\right)
$$

$\mathrm{CHO}$ oxidation rate $\left(\mathrm{g} \mathrm{min}^{-1}\right)$

$$
=4.55 \dot{V} \mathrm{CO}_{2}\left(\mathrm{~L} \mathrm{~min}^{-1}\right)-3.21 \dot{V} \mathrm{O}_{2}\left(\mathrm{~L} \mathrm{~min}^{-1}\right)
$$

The energy expenditure ( $\mathrm{kcal} \mathrm{min}^{-1}$ ) from fat and carbohydrates was calculated by multiplying the fat and $\mathrm{CHO}$ oxidation rates by the energy equivalents of fat $(1 \mathrm{~g}=9 \mathrm{kcal})$ and $\mathrm{CHO}(1 \mathrm{~g}=4 \mathrm{kcal})$. For each participant, the results of the graded exercise tests until a RER of 1.0 was reached were used to calculate fat oxidation rates over a wide range of exercise intensities. To model and characterize the whole-body fat oxidation kinetics, represented as a function of exercise intensity, and to determine $\mathrm{Fat}_{\max }$ and MFO, the SIN model (Cheneviere et al. 2009b) was used. The SIN model includes three independent variables representing the main quantitative characteristics of the curve: dilatation, symmetry and translation. Dilatation refers to the degree of dilatation or retraction of the curve, the symmetry variable is used to break the symmetry of the standard basic sine curve, and translation refers to translation of the whole curve toward the abscissa axis (Cheneviere et al. 2009b):

$\% \mathrm{MFO}=\operatorname{Sin}\left\{\left[\frac{\pi^{\frac{1}{s}}}{\pi+2 d}\left(K \% \dot{V} \mathrm{O}_{2 \max }+d+t\right)\right]^{s}\right\}$

where $d, s$ and $t$ are, respectively, the variables of dilatation, symmetry and translation, and $K$ was the constant of intensity that corresponded to $(\pi / 100)$.

The basic values of 0 for dilatation, 1 for symmetry and 0 for translation determine a symmetric curve that has intersections with the abscissa axis at $(0,0)$ and $(100,0)$ (i.e., 0 and $100 \% \dot{V} \mathrm{O}_{2 \max }$ ). This basic curve could therefore be modulated to fit the experimental data (i.e., fat oxidation rates) and to model the fat oxidation kinetics by independently changing the values of these three variables using an iterative procedure by minimizing the sum of the mean squares of the differences between the estimated energy derived from lipid $\left(E_{\text {lipid }}\right)$ based on the SIN model and the calculated values of $E_{\text {lipid }}$, as previously described (Cheneviere et al. 2009a). For each participant, Fat ${ }_{\max }$ was calculated by differentiation of the SIN model equation, and fat oxidation rate was determined every $5 \% \quad \dot{V} \mathrm{O}_{2 \max }$ between 20 and $85 \% \quad \dot{V} \mathrm{O}_{2 \max }$. The $\mathrm{Fat}_{\max }$ zone was determined as the range of exercise intensities with fat oxidation rates within $10 \%$ of MFO (Achten et al. 2002), with the lower limit referred to as the $\mathrm{Fat}_{\max }$ zone $_{\min }$ and the upper limit as the Fat ${ }_{\max }$ zone $_{\text {max }}$.

\section{Statistical analysis}

All data are presented as mean \pm standard error (SE). Paired Student's $t$ tests were performed to determine the differences in metabolic and respiratory data at different exercise intensities and the differences in the SIN model variables (i.e., dilatation, symmetry and translation) between cycling and running. Pearson product-moment correlations were used to establish relationships between the differences in parameters of fat oxidation kinetics and the independent variables of the SIN model between both modes of exercise. For all statistical analyses, significance was accepted at $P<0.05$. 
Table 1 Participant physical characteristics

Values are mean $\pm \mathrm{SE}$ $n$ number of participants, $B M I$ body mass index, $F M$ fat mass, FFM fat-free mass

a Index of physical activity estimated from a self-reported questionnaire (Baecke et al. 1982)

\section{Results}

\section{Participant characteristics}

The physical characteristics of the study participants are listed in Table 1. Table 2 presents maximal performance values [i.e., $\dot{V} \mathrm{O}_{2 \max }$ and maximal $\mathrm{HR}\left(\mathrm{HR}_{\max }\right)$ ], $\mathrm{VT}_{1}$ and $\mathrm{VT}_{2}$ determined during the cycling and running incremental tests. The volunteers reached a similar maximal HR $(P=0.09), \dot{V} \mathrm{O}_{2 \max }(P=0.69), \mathrm{VT}_{1}(P=0.55)$ and $\mathrm{VT}_{2}$ $(P=0.64)$ in both modes of exercise.

HR, RER and relative substrate oxidation

Resting HR $(66 \pm 3$ and $68 \pm 3, P=0.54)$ and RER $(0.83 \pm 0.02$ and $0.81 \pm 0.02, P=0.13)$ were similar between cycling and running, respectively. During exercise, RER appeared to be significantly greater from 55 to $85 \% \quad \dot{V} \mathrm{O}_{2 \max }$ during cycling compared with running (Fig. 1; $P<0.05$ ). When substrate oxidation was expressed as a percentage of total EE, the relative contribution of fat was higher in running at high exercise intensities $\left(>55 \% \dot{V} \mathrm{O}_{2 \max }\right)$. Concomitantly, the relative contribution of $\mathrm{CHO}$ to $\mathrm{EE}$ from 55 to $85 \% \dot{V} \mathrm{O}_{2 \max }$ was higher in cycling (Fig. 2; $P<0.05$ ).

Table 2 Maximal incremental tests in cycling and running $(n=13)$

\begin{tabular}{lrr}
\hline & \multicolumn{1}{c}{ Cycling } & \multicolumn{1}{c}{ Running } \\
\hline$\dot{V} \mathrm{O}_{2 \max }\left(\mathrm{mL} \mathrm{kg}^{-1} \mathrm{~min}^{-1}\right)$ & $56.2 \pm 1.4$ & $55.7 \pm 1.1$ \\
$\mathrm{HR}_{\max }($ beats min & -1 \\
$\mathrm{VT}_{2}\left(\mathrm{~mL} \mathrm{~kg}^{-1} \mathrm{~min}^{-1}\right)$ & $182.9 \pm 2.0$ & $185.9 \pm 2.5$ \\
$\mathrm{VT}_{2}\left(\% \dot{V} \mathrm{O}_{2 \max }\right)$ & $48.7 \pm 1.3$ & $48.1 \pm 1.1$ \\
$\mathrm{VT}_{1}\left(\mathrm{~mL} \mathrm{~kg}^{-1} \min ^{-1}\right)$ & $86.7 \pm 1.1$ & $86.6 \pm 1.3$ \\
$\mathrm{VT}_{1}\left(\% \dot{V} \mathrm{O}_{2 \max }\right)$ & $36.0 \pm 1.5$ & $36.8 \pm 1.1$ \\
\hline
\end{tabular}

Values are mean $\pm \mathrm{SE}$

$n$ number of participants, $\dot{V} O_{2 \max }$ maximal oxygen uptake, $H R_{\max }$ maximal heart rate, $V T_{1}$ and $V T_{2}$ ventilatory thresholds 1 and 2, respectively
Fat oxidation kinetics

Figure 3a shows the mean whole-body fat oxidation kinetics, which are represented as a function of exercise intensity $(\%$ $\dot{V} \mathrm{O}_{2 \max }$ ) that were obtained during both graded exercise tests and constructed with the SIN model. The characteristics of whole-body fat oxidation kinetics in cycling and running are presented in Table 3. MFO was similar between the two modes of exercise $(P=0.39)$, but the intensity at which it occurred was higher during running when compared to cycling $(P<0.001)$. The absolute fat oxidation rates were significantly higher during running, from 70 to $85 \% \dot{V} \mathrm{O}_{2 \max }$ (Fig. 3a; $P<0.05$ ). In addition, the Fat ${ }_{\max }$ zone was greater $\left(25.6 \pm 0.8\right.$ and $\left.28.4 \pm 0.7 \% \quad \dot{V} \mathrm{O}_{2 \max } ; P=0.001\right)$ and occurred at a significantly higher exercise intensity $(P<0.001)$ during the treadmill protocol than during cycling.

SIN model variables

Figure $3 b$ provides a graphical representation of the mean relative whole-body fat oxidation kinetics, which are expressed as a percentage of MFO, that were obtained during the treadmill and cycle ergometer tests. The shapes of the curves are characterized by the three variables of the SIN model, which are presented in Table 4 . The mean fat oxidation kinetics in cycling formed a symmetric parabolic curve (symmetry $\sim 1$ ), whereas the fat oxidation kinetics during running was characterized by a rightward asymmetry (Fig. 3b). The variables of dilatation and symmetry were significantly greater in running than in cycling (Table 4, $P<0.001$ and $P=0.011$, respectively). The whole-body fat oxidation kinetics determined during both tests was therefore different. In addition, delta (i.e., the difference between cycling and running) MFO was positively correlated with delta dilatation $(r=0.68, P=0.01)$, while delta Fat ${ }_{\max }$ was correlated with delta symmetry $(r=0.88, P<0.001)$.

\section{Discussion}

The aim of the present study was to quantitatively describe and compare whole-body fat oxidation kinetics during 
Fig. 1 Mean respiratory exchange ratio (RER) values during cycling and running incremental tests $(n=13)$. $\dot{V} O_{2 \max }$ maximal oxygen uptake. Values are mean $\pm \mathrm{SE}$; $n$ number of participants. *Significant differences between cycling and running, $P<0.05$

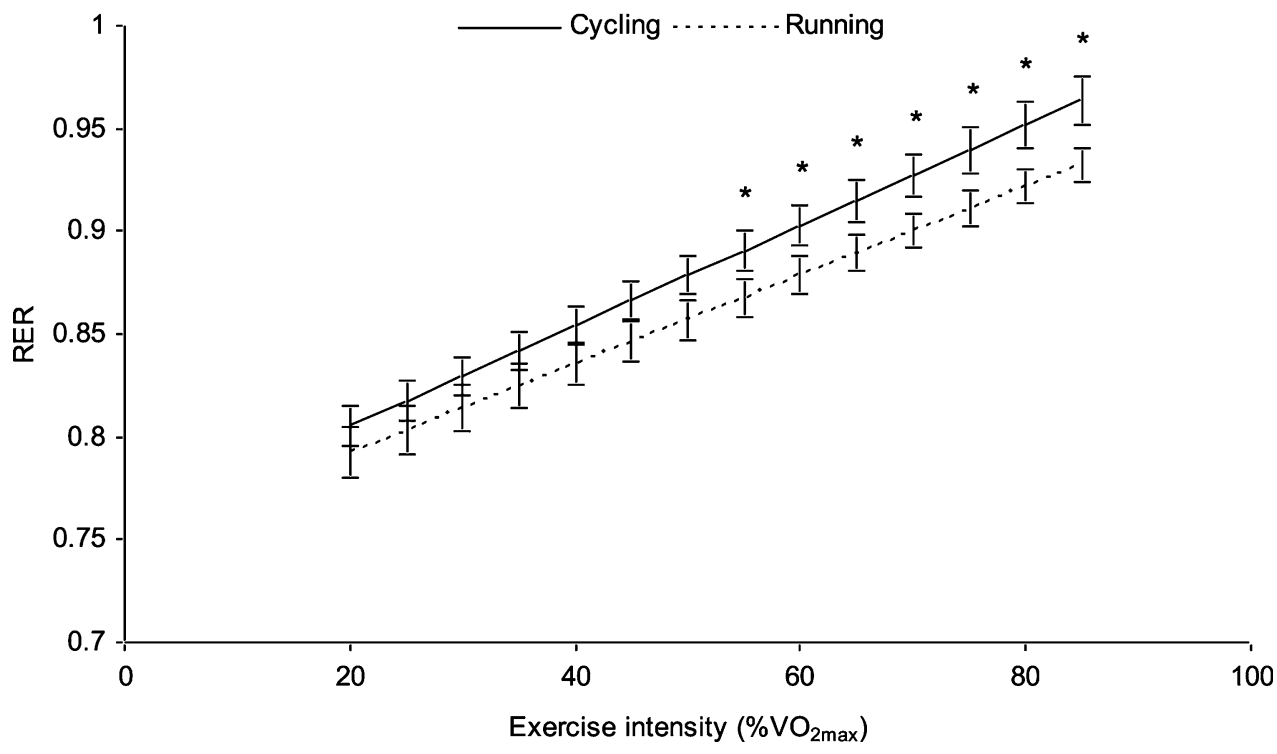

Fig. 2 Relative contribution of carbohydrate $(\mathrm{CHO})$ and fat to total energy expenditure (EE) during cycling and running incremental tests $(n=13)$. $\dot{V} O_{2 \max }$ maximal oxygen uptake. Values are mean $\pm \mathrm{SE}$; $n$ number of participants. *Significant differences in relative contribution of $\mathrm{CHO}$ and fat to EE between cycling and running, $P<0.05$

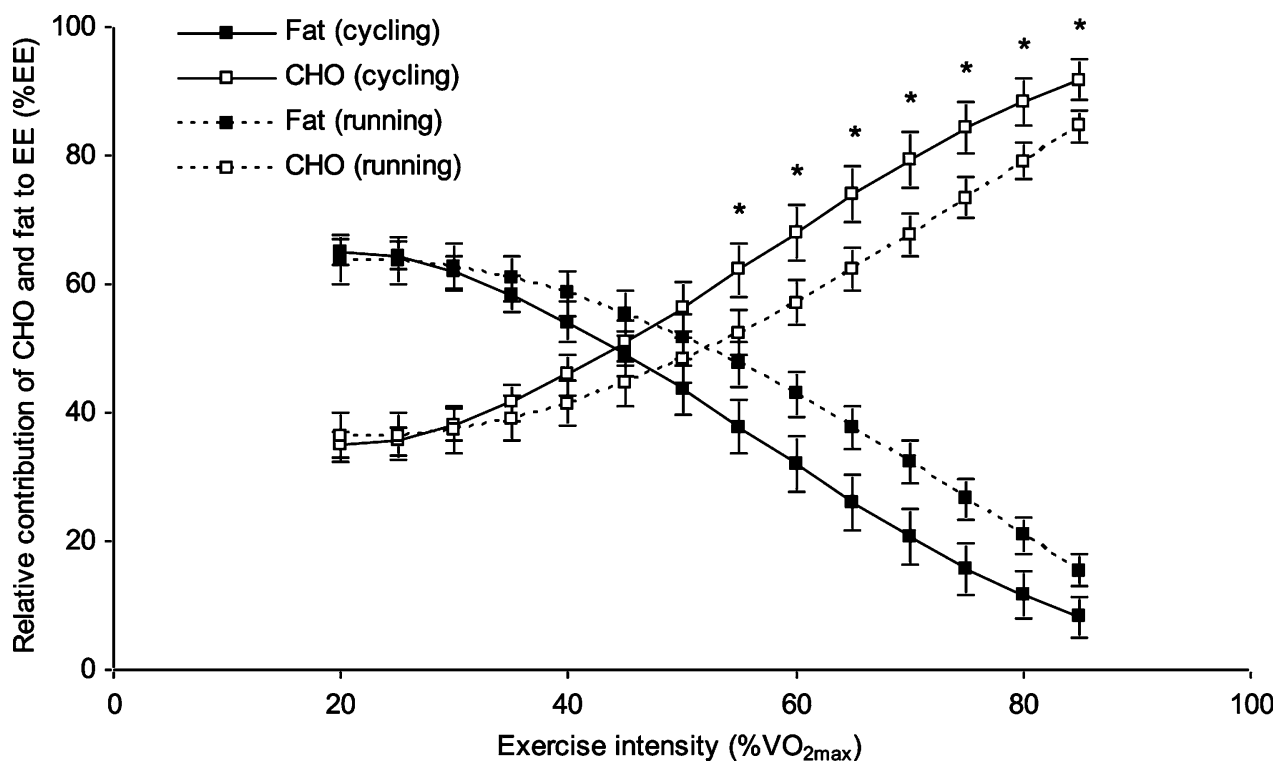

graded exercise tests in cycling and running using a mathematical model. The main finding of this investigation was that the fat oxidation kinetics characterized by the three variables of the SIN model (i.e., dilatation, symmetry and translation) were different between the two exercise modes. Indeed, as hypothesized, the variable of dilatation was significantly greater in running as compared with cycling. At the same time, the mean running fat oxidation kinetics was also characterized by a rightward asymmetry. Fat $_{\max }$ and fat oxidation rates from 70 to $85 \% \dot{V} \mathrm{O}_{2 \max }$ were also significantly higher for running compared with cycling, whereas MFO was not influenced by the mode of exercise.

Fat and CHO utilization depends largely on exercise intensity (Romijn et al. 1993; van Loon et al. 2001). In the present study, Fat ${ }_{\max }$ occurred at an intensity of $44 \%$
$\dot{V} \mathrm{O}_{2 \max }$ during cycling and $57 \% \dot{V} \mathrm{O}_{2 \max }$ while running, which is in line with previous investigations [i.e., cycling: $62 \% \dot{V} \mathrm{O}_{2 \max }$ (Achten et al. 2003), $44 \% \dot{V} \mathrm{O}_{2 \max }$ (Nordby et al. 2006); uphill walking: $59 \% \dot{V} \mathrm{O}_{2 \max }$ (Achten et al. 2003), $45 \% \dot{V} \mathrm{O}_{2 \max }$ for men and $52 \% \dot{V} \mathrm{O}_{2 \max }$ for women (Venables et al. 2005)]. Although Fat max $_{\max }$ occurred at a higher exercise intensity in running when compared with cycling, MFO was not significantly different between both modes of exercise. On the other hand, the absolute fat oxidation rates were significantly higher during the treadmill exercise from $70 \% \dot{V} \mathrm{O}_{2 \max }$, which is in agreement with previous findings (Achten et al. 2003; Knechtle et al. 2004; Snyder et al. 1993). In addition, the RER values were also significantly higher in cycling than in running from 55 to $85 \% \dot{V} \mathrm{O}_{2 \max }$ (Fig. 1), which confirmed the results of other investigations (Achten et al. 2003; Snyder et al. 
Fig. 3 Mean whole-body fat oxidation kinetics $(n=13)$, in absolute (a) and relative (b) values, constructed with the SIN model during cycling and running incremental tests. Data at both extremities of the relative fat oxidation kinetics (b) were extrapolated from the SIN model (dashed lines). $\dot{V} O_{2 \max }$ maximal oxygen uptake, $M F O$ maximal fat oxidation. Values are mean \pm SE; $n$ number of participants. *Significant differences between cycling and running, $P<0.05$
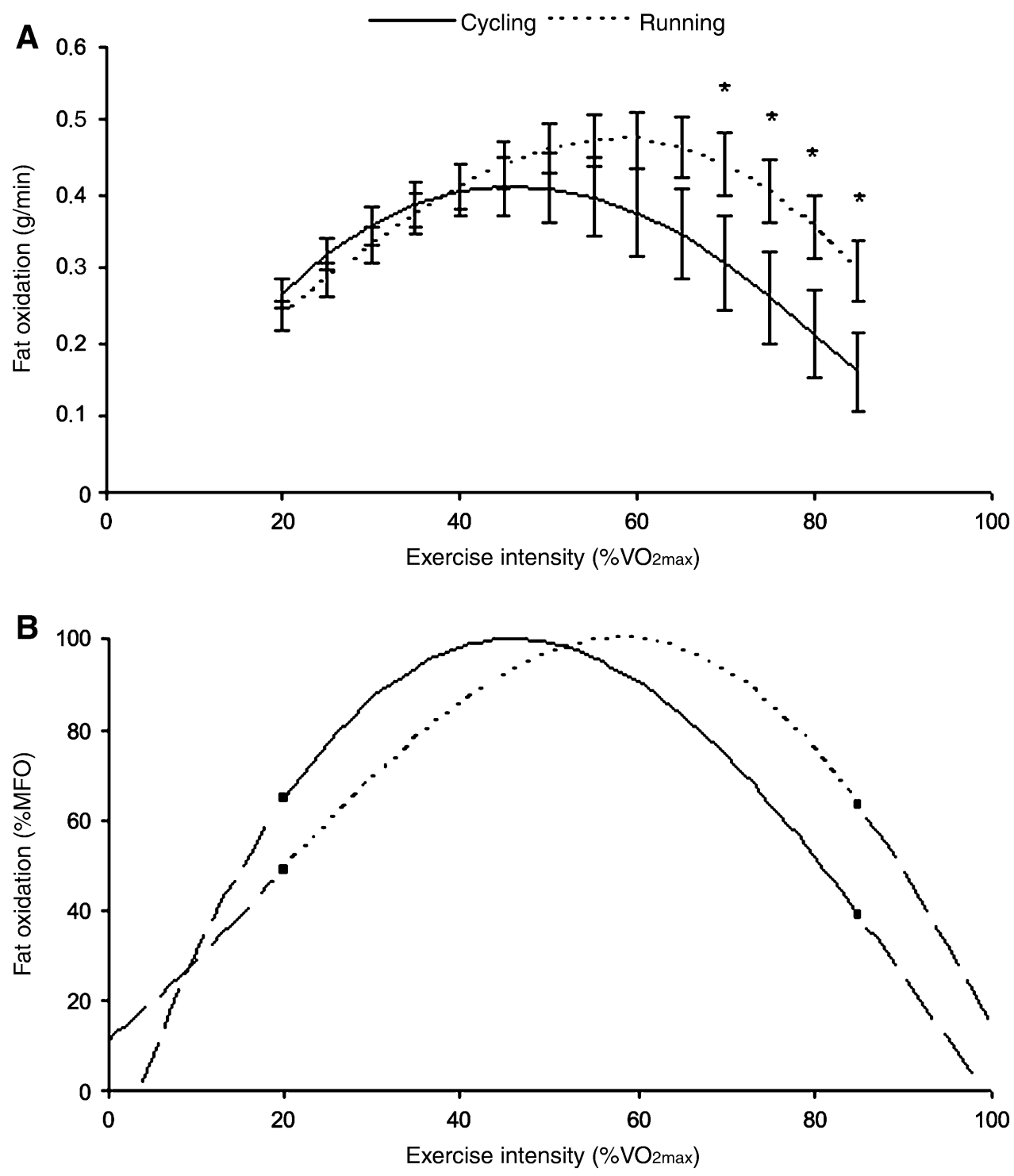

1993). Concomitantly, when substrate oxidation was expressed as a percentage of total energy expenditure, the relative contribution of fat was higher in running at high exercise intensities, whereas the relative contribution of $\mathrm{CHO}$ to the total EE was higher in cycling (Fig. 2).

To our knowledge, the present study is the first to additionally characterize the shape of whole-body fat oxidation kinetics during cycling and running using a mathematical model (Cheneviere et al. 2009b), while previous investigations (Achten et al. 2002, 2003; Stisen et al. 2006) only determined Fat ${ }_{\max }$ and MFO. Figure 3 presents the mean fat oxidation kinetics determined during the treadmill and cycle ergometer incremental tests. While Fig. 3a shows absolute values, which highlights the differences in the fat oxidation rates between the two modes of exercise, Fig. $3 \mathrm{~b}$ presents the mean relative fat oxidation kinetics (i.e., \%MFO), which clearly quantifies the differences in the shape of the kinetics by the mean of the three variables (Table 4). With a symmetry value of 0.97 and dilatation and translation values around 0 , the whole-body fat oxidation kinetics in cycling is a symmetric parabolic curve with MFO occurring near $50 \% \dot{V} \mathrm{O}_{2 \max }$. This shape, which is in agreement with previously observed curves (Achten et al. 2002, 2003; Stisen et al. 2006), seems to be representative of healthy, moderately trained individuals during cycling. At the same time, the fat oxidation kinetics during running appears to be different as it is characterized by a greater dilatation and a rightward asymmetry when compared with cycling (Table 4).

Several physiological and mechanical differences between these two exercise modalities may account for the differences in the shape of the fat oxidation kinetics and the higher fat oxidation rates that were obtained at high exercise intensities during running when compared with 
Table 3 Characteristics of whole-body fat oxidation kinetics in cycling and running $(n=13)$

\begin{tabular}{|c|c|c|}
\hline & Cycling & Running \\
\hline $\operatorname{MFO}\left(\mathrm{g} \mathrm{min}^{-1}\right)$ & $0.44 \pm 0.05$ & $0.48 \pm 0.04$ \\
\hline $\mathrm{Fat}_{\max }\left(\% \dot{V} \mathrm{O}_{2 \max }\right)$ & $44.2 \pm 2.9$ & $57.2 \pm 1.5^{* *}$ \\
\hline $\mathrm{Fat}_{\max }\left(\% \dot{V} \mathrm{O}_{2 \text { reserve }}\right)$ & $38.7 \pm 3.2$ & $52.7 \pm 1.7 * *$ \\
\hline $\mathrm{Fat}_{\max }\left(\% \mathrm{HR}_{\max }\right)$ & $60.7 \pm 2.1$ & $68.3 \pm 1.5^{*}$ \\
\hline $\mathrm{Fat}_{\max }\left(\% \mathrm{HR}_{\text {reserve }}\right)$ & $38.4 \pm 3.6$ & $49.9 \pm 2.3^{*}$ \\
\hline $\mathrm{Fat}_{\max }$ zone $\left(\% \dot{V} \mathrm{O}_{2 \max }\right)$ & $25.6 \pm 0.8$ & $28.4 \pm 0.7 * *$ \\
\hline Fat $_{\max }$ zone $_{\min }\left(\% \dot{V} \mathrm{O}_{2 \max }\right)$ & $31.8 \pm 2.6$ & $42.7 \pm 1.5^{* *}$ \\
\hline Fat $_{\max }$ zone $_{\max }\left(\% \dot{V} \mathrm{O}_{2 \max }\right)$ & $57.4 \pm 2.9$ & $71.1 \pm 1.5^{* *}$ \\
\hline RER $_{\text {Fatmax }}$ & $0.86 \pm 0.00$ & $0.87 \pm 0.01$ \\
\hline
\end{tabular}

Values are mean \pm SE. Significant differences between cycling and running, ${ }^{*} P<0.05, * * P<0.001$

$n$ number of participants, Fat $t_{\max }$ exercise intensity at which the maximal fat oxidation rate (MFO) occurs, $\dot{V} O_{2 \max }$ maximal oxygen uptake, $\dot{V} \mathrm{O}_{2 \text { reserve }} \dot{V} \mathrm{O}_{2}$ reserve $\left(\dot{V} \mathrm{O}_{2 \max }-\dot{V} \mathrm{O}_{2 \text { rest }}\right), F a t_{\text {max }}$ zone range of exercise intensities with fat oxidation rates within $10 \%$ of MFO, Fat $_{\text {max }}$ zone $_{\text {min }}$ lower limit of Fat max $_{\text {zone, }}$ Fat $_{\text {max }}$ zone $_{\max }$ upper limit of Fat $_{\text {max }}$ zone, $F F M$ fat-free mass, $R E R$ respiratory exchange ratio, $H R_{\text {max }}$ maximal heart rate, $H R_{\text {reserve }} \mathrm{HR}$ reserve $\left(\mathrm{HR}_{\max }-\mathrm{HR}_{\text {rest }}\right)$

Table 4 Variables of the SIN model in cycling and running $(n=13)$

\begin{tabular}{lrl}
\hline & \multicolumn{1}{c}{ Cycling } & \multicolumn{1}{l}{ Running } \\
\hline Dilatation & $-0.10 \pm 0.07$ & $0.22 \pm 0.05^{* *}$ \\
Symmetry & $0.97 \pm 0.11$ & $1.37 \pm 0.10^{*}$ \\
Translation & $0.08 \pm 0.08$ & $0.10 \pm 0.07$ \\
\hline
\end{tabular}

Values are mean \pm SE. Significant differences between cycling and running, $* P<0.05, * * P<0.001$

$n$ number of participants

cycling. First, the greater muscle mass involved in running, which is mainly due to the stabilization of the trunk and arms (Arkinstall et al. 2001; Hermansen and Saltin 1969; Knechtle et al. 2004; Koyal et al. 1976), may contribute to the higher fat oxidation rates and the greater dilatation of the fat oxidation kinetics found during the treadmill exercise. In fact, changes in MFO between cycling and running were significantly correlated with changes in the dilatation of the kinetics $(r=0.68, P=0.01)$. The variable of dilatation therefore seems to be a general and sensitive marker of the ability to oxidize fat during exercise and confirms previous results (Cheneviere et al. 2009b). Second, the different muscle contraction regimens involved in running and cycling (Arkinstall et al. 2001; Bijker et al. 2002; Carter et al. 2000) may account for the differences in the symmetry of the fat oxidation kinetics between these two exercises. While concentric actions dominate in cycling, running has an eccentric component during the landing phase. The "preloading" of muscle during the eccentric phase of the SSC in running may improve the efficiency of the subsequent concentric phase (Cavagna 1977). It is therefore possible that the greater storage and return of elastic energy may delay the onset of peripheral fatigue and/or reduce the recruitment of larger motor units that consist of more type II muscle fibres during running in comparison to cycling for same relative exercise intensity (Carter et al. 2000). This may lead to higher CHO oxidation rates, higher lactate production (Knechtle et al. 2004) and reduction in muscle $\mathrm{pH}$ in cycling which can inhibit the activity of carnitine palmitoyl transferase I (i.e., key enzyme in fat metabolism) (Starritt et al. 2000). This may explain the lower $\mathrm{Fat}_{\max }$ in cycling and the rightward asymmetry in the running fat oxidation kinetics. In fact, differences in $\mathrm{Fat}_{\max }$ between cycling and running were significantly correlated with differences in the variable of symmetry $(r=0.88, P<0.001)$. Moreover, Achten et al. (2003), comparing two "similar" exercises with predominantly concentric contractions (i.e., cycling vs. uphill walking), found similar values of $\mathrm{Fat}_{\max }$ and global shape of the curves for both modes of exercise. Therefore, the various physiological and mechanical effects that are related to the specific type of muscle contraction in running (i.e., SSC) may be linked to the later reliance on $\mathrm{CHO}$ as compared to cycling, implying a shift of Fat $_{\max }$ to the higher exercise intensities.

Some methodological limitations exist and need to be addressed. First, it is not usual that $\dot{V} \mathrm{O}_{2 \max }$ values for cycling and running are similar. Indeed, it has been traditionally shown that $\dot{V} \mathrm{O}_{2 \text { max }}$ is 3-11\% lower during cycling than running (Achten et al. 2003; Basset and Boulay 2000; Carter et al. 2000; Nieman et al. 1998). In some studies, however, no significant difference in $\dot{V} \mathrm{O}_{2 \max }$ was found between these two modes of exercise (Billat et al. 1998; Hermansen and Saltin 1969), which suggests that $\dot{V} \mathrm{O}_{2 \max }$ values are also dependent upon the specific training of an athlete (Basset and Boulay 2000). In the present investigation, six of the volunteers were more "cycling-oriented" than "running-oriented", which may partly explain the similar $\dot{V} \mathrm{O}_{2 \max }$ reached during the cycling and running incremental tests. About the duration of the running incremental test, participants exercised at a submaximal level (i.e., until RER $=1.0$ ) during $37 \pm 1 \mathrm{~min}$ for a total duration (i.e., until exhaustion) of $41 \pm 1 \mathrm{~min}$, which was slightly longer than the cycling test $(31 \pm 3$ and $36 \pm 2$, respectively, $P<0.05$ ). On the other hand, participants first walked until $7 \mathrm{~km} \mathrm{~h}^{-1}$, which represented $17 \mathrm{~min}$. At the same time, an exercise at intensity below the lactate threshold can be sustained for a long period with a modest sense of effort (Whipp and Rossiter 2005). When taking in account only stages with exercise intensity above $\mathrm{VT}_{1}$, the running and cycling tests were of similar duration $(15.6 \pm 1.3$ and $14.2 \pm 1.6$, respectively, $P=0.49)$. Moreover, in a recent review authors concluded that 
current evidence suggests that to elicit valid $\dot{V} \mathrm{O}_{2 \max }$ values, running incremental tests should generally last between 5 and $26 \mathrm{~min}$, in both trained and untrained individuals (Midgley et al. 2008). Finally, all participants met the maximal criteria. It could therefore be assumed that running $\dot{V} \mathrm{O}_{2 \text { max }}$ was not underestimated and that study participants reached their $\dot{V} \mathrm{O}_{2 \max }$, implying the possibility to compare the two modes of exercise at similar exercise intensity. Furthermore, as the investigation of gender differences in fat oxidation kinetics was not within the objectives of the present study, neither the phase within the menstrual cycles nor the presence/absence of oral contraceptives were controlled for. However, there is no consensus about the modifications in substrate oxidation during exercise across the menstrual cycle (Horton et al. 2002; Zderic et al. 2001). Moreover, as the experimental protocol was designed to determine the response of a mixed and heterogeneous group of moderately active individuals to two different modes of exercise (i.e., repeated measures statistical design), the small samples in both sexes were therefore not compared because of potential type II statistical errors.

In conclusion, this study shows that whole-body fat oxidation kinetics that were obtained during graded exercise tests and described with the three independent variables of the SIN model (i.e., dilatation, symmetry and translation) were significantly different between cycling and running. While the mean fat oxidation kinetics in cycling was a symmetric parabolic curve, the fat oxidation kinetics during running was characterized by a greater dilatation and a rightward asymmetry. The greater dilatation may be mainly related to the higher fat oxidation rates due to the larger muscle mass involved in running, while the rightward asymmetry, which reflects the higher values of Fat ${ }_{\text {max }}$ compared with cycling, may be induced by the specific type of muscle contraction. However, future studies should determine the exact mechanisms behind the differences in substrate oxidation between these two modes of exercise.

\section{References}

Achten J, Gleeson M, Jeukendrup AE (2002) Determination of the exercise intensity that elicits maximal fat oxidation. Med Sci Sports Exerc 34:92-97

Achten J, Venables MC, Jeukendrup AE (2003) Fat oxidation rates are higher during running compared with cycling over a wide range of intensities. Metabolism 52:747-752

Arkinstall MJ, Bruce CR, Nikolopoulos V, Garnham AP, Hawley JA (2001) Effect of carbohydrate ingestion on metabolism during running and cycling. J Appl Physiol 91:2125-2134

Baecke JA, Burema J, Frijters JE (1982) A short questionnaire for the measurement of habitual physical activity in epidemiological studies. Am J Clin Nutr 36:936-942
Basset FA, Boulay MR (2000) Specificity of treadmill and cycle ergometer tests in triathletes, runners and cyclists. Eur J Appl Physiol 81:214-221

Beaver WL, Wasserman K, Whipp BJ (1986) A new method for detecting anaerobic threshold by gas exchange. J Appl Physiol 60:2020-2027

Bergman BC, Brooks GA (1999) Respiratory gas-exchange ratios during graded exercise in fed and fasted trained and untrained men. J Appl Physiol 86:479-487

Bergman BC, Butterfield GE, Wolfel EE, Casazza GA, Lopaschuk GD, Brooks GA (1999) Evaluation of exercise and training on muscle lipid metabolism. Am J Physiol 276:E106-E117

Bijker KE, de Groot G, Hollander AP (2002) Differences in leg muscle activity during running and cycling in humans. Eur $\mathbf{J}$ Appl Physiol 87:556-561

Billat VL, Richard R, Binsse VM, Koralsztein JP, Haouzi P (1998) The $\mathrm{V}(\mathrm{O} 2)$ slow component for severe exercise depends on type of exercise and is not correlated with time to fatigue. J Appl Physiol 85:2118-2124

Carter J, Jeukendrup AE (2002) Validity and reliability of three commercially available breath-by-breath respiratory systems. Eur J Appl Physiol 86:435-441

Carter H, Jones AM, Barstow TJ, Burnley M, Williams CA, Doust JH (2000) Oxygen uptake kinetics in treadmill running and cycle ergometry: a comparison. J Appl Physiol 89:899-907

Carter SL, Rennie C, Tarnopolsky MA (2001) Substrate utilization during endurance exercise in men and women after endurance training. Am J Physiol Endocrinol Metab 280:E898-E907

Cavagna GA (1977) Storage and utilization of elastic energy in skeletal muscle. Exerc Sport Sci Rev 5:89-129

Cheneviere X, Borrani F, Ebenegger V, Gojanovic B, Malatesta D (2009a) Effect of a 1-hour single bout of moderate-intensity exercise on fat oxidation kinetics. Metabolism 58:1778-1786

Cheneviere X, Malatesta D, Peters EM, Borrani F (2009b) A mathematical model to describe fat oxidation kinetics during graded exercise. Med Sci Sports Exerc 41:1615-1625

Coyle EF, Jeukendrup AE, Oseto MC, Hodgkinson BJ, Zderic TW (2001) Low-fat diet alters intramuscular substrates and reduces lipolysis and fat oxidation during exercise. Am J Physiol Endocrinol Metab 280:E391-E398

Durnin JV, Womersley J (1973) Total body fat, calculated from body density, and its relationship to skinfold thickness in 571 people aged 12-72 years. Proc Nutr Soc 32:45A

Frayn KN (1983) Calculation of substrate oxidation rates in vivo from gaseous exchange. J Appl Physiol 55:628-634

Hermansen L, Saltin B (1969) Oxygen uptake during maximal treadmill and bicycle exercise. J Appl Physiol 26:31-37

Horton TJ, Pagliassotti MJ, Hobbs K, Hill JO (1998) Fuel metabolism in men and women during and after long-duration exercise. J Appl Physiol 85:1823-1832

Horton TJ, Miller EK, Glueck D, Tench K (2002) No effect of menstrual cycle phase on glucose kinetics and fuel oxidation during moderate-intensity exercise. Am J Physiol Endocrinol Metab 282:E752-E762

Knechtle B, Muller G, Willmann F, Kotteck K, Eser P, Knecht H (2004) Fat oxidation in men and women endurance athletes in running and cycling. Int J Sports Med 25:38-44

Koyal SN, Whipp BJ, Huntsman D, Bray GA, Wasserman K (1976) Ventilatory responses to the metabolic acidosis of treadmill and cycle ergometry. J Appl Physiol 40:864-867

Midgley AW, Bentley DJ, Luttikholt H, McNaughton LR, Millet GP (2008) Challenging a dogma of exercise physiology: does an incremental exercise test for valid $V \mathrm{O}_{2 \max }$ determination really need to last between 8 and 12 minutes? Sports Med 38:441-447

Nieman DC, Nehlsen-Cannarella SL, Fagoaga OR, Henson DA, Utter A, Davis JM, Williams F, Butterworth DE (1998) Effects of 
mode and carbohydrate on the granulocyte and monocyte response to intensive, prolonged exercise. J Appl Physiol 84:1252-1259

Nordby P, Saltin B, Helge JW (2006) Whole-body fat oxidation determined by graded exercise and indirect calorimetry: a role for muscle oxidative capacity? Scand J Med Sci Sports 16:209214

Perez-Martin A, Dumortier M, Raynaud E, Brun JF, Fedou C, Bringer J, Mercier J (2001) Balance of substrate oxidation during submaximal exercise in lean and obese people. Diabetes Metab 27:466-474

Romijn JA, Coyle EF, Sidossis LS, Gastaldelli A, Horowitz JF, Endert E, Wolfe RR (1993) Regulation of endogenous fat and carbohydrate metabolism in relation to exercise intensity and duration. Am J Physiol 265:E380-E391

Sidossis LS, Wolfe RR, Coggan AR (1998) Regulation of fatty acid oxidation in untrained vs. trained men during exercise. Am J Physiol 274:E510-E515

Snyder AC, O'Hagan KP, Clifford PS, Hoffman MD, Foster C (1993) Exercise responses to in-line skating: comparisons to running and cycling. Int J Sports Med 14:38-42

Starritt EC, Howlett RA, Heigenhauser GJ, Spriet LL (2000) Sensitivity of CPT I to malonyl-CoA in trained and untrained human skeletal muscle. Am J Physiol Endocrinol Metab 278:E462-E468

Stisen AB, Stougaard O, Langfort J, Helge JW, Sahlin K, Madsen K (2006) Maximal fat oxidation rates in endurance trained and untrained women. Eur J Appl Physiol 98:497-506

van Loon LJ, Greenhaff PL, Constantin-Teodosiu D, Saris WH, Wagenmakers AJ (2001) The effects of increasing exercise intensity on muscle fuel utilisation in humans. J Physiol 536:295-304

Venables MC, Achten J, Jeukendrup AE (2005) Determinants of fat oxidation during exercise in healthy men and women: a crosssectional study. J Appl Physiol 98:160-167

Wasserman K, Hansen JE, Sue AY, Whipp BJ, Casaburi R (1994) Principles of exercise testing and interpretation, Second edn. Lippincott Williams \& Wilkins, Philadelphia

Whipp BJ, Rossiter HB (2005) The kinetics of oxygen uptake: physiological inferences from the parameters. In: Jones AM, Poole DC (eds) Oxygen uptake kinetics in sport exercise and medicine. Routledge, London, pp 62-93

Zderic TW, Coggan AR, Ruby BC (2001) Glucose kinetics and substrate oxidation during exercise in the follicular and luteal phases. J Appl Physiol 90:447-453 